\title{
Highly Sensitive Electrochemical Sensor for the Determination of 8-Hydroxy-2' -deoxyguanosine Incorporating SWCNTs-Nafion Composite Film
}

\author{
Lingfei Yang, ${ }^{1}$ Bing Wang, ${ }^{1}$ Honglan Qi, ${ }^{1}$ Qiang Gao, \\ Chen-zhong Li, ${ }^{2}$ and Chengxiao Zhang ${ }^{1}$ \\ ${ }^{1}$ Key Laboratory of Analytical Chemistry for Life Science of Shaanxi Province, School of Chemistry and Chemical Engineering, \\ Shaanxi Normal University, Xi'an 710062, China \\ ${ }^{2}$ Nanobioengineering/Bioelectronics Laboratory, Department of Biomedical Engineering, Florida International University, \\ Miami, FL 33174, USA
}

Correspondence should be addressed to Chen-zhong Li; licz@fiu.edu and Chengxiao Zhang; cxzhang@snnu.edu.cn

Received 21 April 2015; Revised 26 July 2015; Accepted 4 August 2015

Academic Editor: Josep Samitier

Copyright (C) 2015 Lingfei Yang et al. This is an open access article distributed under the Creative Commons Attribution License, which permits unrestricted use, distribution, and reproduction in any medium, provided the original work is properly cited.

\begin{abstract}
8-Hydroxy-2 ${ }^{\prime}$-deoxyguanosine $(8-\mathrm{OHdG})$ is a typical biomarker of oxidative DNA damage and has attracted much attention in recent years since the level of 8-OHdG in body fluids is typically associated with various diseases. In this work, a simple and highly sensitive electrochemical sensor for the determination of 8-OHdG was fabricated incorporating single wall carbon nanotubes(SWCNTs-) Nafion composite film coated on glassy carbon electrode. Nafion was chosen as an optimal adhesive agent from a series of adhesive agents and acted as a binder, enrichment, and exclusion film. Due to the strong cation-exchange ability of Nafion and the outstanding electronic properties of SWCNTs, the prepared SWCNTs-Nafion film can strongly enhance the electrochemical response to oxidation of $8-\mathrm{OHdG}$ and efficiently alleviate the interferences from uric acid and ascorbic acid. The oxidation peak currents are linear with the concentration of $8-\mathrm{OHdG}$ in the range of 0.03 to $1.25 \mu \mathrm{M}$ with a detection limit of $8.0 \mathrm{nM}(\mathrm{S} / \mathrm{N}=3)$. This work demonstrates that SWCNTs-Nafion film can improve the sensitivity, selectivity, reproducibility, and stability, making it an ideal candidate for electrochemical detection of 8-OHdG.
\end{abstract}

\section{Introduction}

8-Hydroxy-2' -deoxyguanosine (8-OHdG), an oxidized form of the nucleoside $2^{\prime}$-deoxyguanosine $\left(2^{\prime}\right.$-dG), is well known as an important biomarker of oxidative DNA damage [1-3]. It is generated in the reaction between the eighth position of the guanine molecule of DNA and reactive oxygen species such as hydroxyl radicals, superoxide radicals, and hydrogen peroxide [2]. The level of 8-OHdG in body fluids is typically associated with the cancers $[2,4]$, diabetes $[5,6]$, aging [7], and neurological disorders $[8,9]$. Nowadays, it also acts as a significant biomarker of genotoxicity [10, 11]. The development of analytical methods for the determination of 8OHdG with simplicity, high sensitivity, and selectivity is of great importance in clinic tests.
The analytical methods for quantifying 8-OHdG have been developed, including high-performance liquid chromatography-electrochemical detection [12], high-performance liquid chromatography-electrochemical detection combined with solid-phase extraction [13, 14], gas/liquid chromatography-mass spectrometry $[15,16]$ or liquid chromatography-mass spectrometry [17-19], enzyme-linked immunosorbent assay $[20,21]$, and capillary electrophoresis amperometric detection after solid-phase extraction [22, 23]. These methods provide high sensitivity and high throughput. However, most of these methods have obvious drawbacks; for example, they either require sophisticated equipment and trained personnel or involve tedious pretreatment procedures such as solid-phase extraction. Electrochemical methods for quantifying 8-OHdG, based on the electrochemical oxidation 
activity of 8-OHdG, have displayed many advantages, such as high sensitivity, their fast implementation, and the simplicity of the instruments. In direct electrochemical methods, most of them are conducted at bare electrodes. Langmaier et al. [24] investigated the electrochemical oxidation mechanism of 8-OHdG at glassy carbon electrode (GCE) and Au, Pt, and $\mathrm{SnO}_{2}$ electrode using cyclic voltammetry and indicated that the rate of the charge transfer reaction decreased with the increasing solution $\mathrm{pH}$ and depended on the nature of the electrode material following the sequence $\mathrm{GC}>\mathrm{Pt}, \mathrm{Au} \gg$ $\mathrm{SnO}_{2}$. Rebelo et al. [25] reported a pH-dependent oxidation mechanism over a wide $\mathrm{pH}$ range of 1-12 and the best sensitivity observed at $\mathrm{pH} 6$ for the differential pulse voltammetry (DPV) determination of 8 -OHdG in the presence of uric acid with GCE. Brett et al. [26] reported electrochemical oxidation of 8-oxoguanine on GCE for the detection of DNA damage with a detection limit of $0.8 \mu \mathrm{M}$. In a nutshell, the sensitivity and selectivity of direct electrochemical methods for quantifying 8-OHdG are limited.

Some efforts have been made to improve the sensitivity and selectivity of electrochemical sensors for quantifying 8-OHdG, mainly by modification of GCE using nanomaterials and polymers. In 2007, Li et al. [27] reported an electrochemical sensor for quantifying $8-\mathrm{OHdG}$ on a poly(3-methylthiophene) modified GCE with a detection limit of $0.10 \mu \mathrm{M}$. Other work [28] they did in 2013 was on the electrochemical reduction synthesis of graphene/Nafion nanocomposite film and their results showed a high level of electrochemical performance on the oxidation of 8-OHdG. A wide linear range of $0.07-33.04 \mu \mathrm{M}$ and a low detection limit of $1.12 \mathrm{nM}$ for 8-OHdG were obtained using linear sweep voltammetry. In 2008, Gutiérrez et al. [29] reported HPLCamperometric detection of 8-OHdG using electrostatic and covalent adsorption of poly(amidoamine) (PAMAM) dendrimers on a thiol-modified gold electrode with a detection limit of $1.2 \mathrm{nM}$ in synthetic samples and matrix interference elimination. In 2011, Gutiérrez et al. [30] also reported differential pulse anodic stripping voltammetry for quantifying $8-\mathrm{OHdG}$ on multiple wall carbon nanotubes (MWCNTs)/polyethylenimine (PEI) modified electrodes with a detection limit of $0.10 \mu \mathrm{M}$ and high selectivity. Electrochemical sensors using nanomaterials and polymers are an efficient way for electrochemical quantification of 8-OHdG.

Carbon nanotubes (CNTs) have a wide application in electrochemical sensors $[31,32]$ and biosensors [33, 34] since they possess the characteristic of unique properties $[31,35$, 36], such as high electrical conductivity, outstanding catalytic activities, high adsorptive property, and facilitating electron transfer. CNTs have two distinct types of structures, including MWCNTs and single wall carbon nanotubes (SWCNTs). MWCNTs are composed of concentric and closed graphene tubules, each with a rolled-up graphene sheet, formed in a range of diameters, typically between 2 and $25 \mathrm{~nm}$. SWCNTs are made of a single graphite sheet rolled seamlessly, with a diameter between 1 and $2 \mathrm{~nm}$, arranged in a regular pattern of bundles that consist of tens to hundreds of nanotubes in parallel and in contact with one another [37]. Moreover, CNTsbased electrochemical sensors have shown many distinct advantages in the analysis of electroactive substances such as cytochrome c [38], dopamine, epinephrine, and ascorbic acid [39] (on SWCNTs/GCE), and NADH [40], myoglobin [41], and warfarin [42] (on MWCNTs/GCE).

Nafion, a perfluorosulfonated and negatively charged polymer, is a cation-exchange polymer. Nafion films have been widely used as an electrode modifier in applications of electrochemical sensors and biosensors because of their chemical and thermal stability, high cation conductivity [43], and high permeability to cations coupled with their near impermeability to anions [44]. Meanwhile, Nafion can also be used as a binder to help other modifiers effectively adhere on substrate electrode [45]. Wang et al. [46] demonstrated CNTs in the presence of Nafion can be homogeneously dispersed into ethanol. To the best of our knowledge, an electrochemical sensor for the determination of 8-OHdG based on SWCNTs-Nafion modified electrode has not been reported.

The aim of this work was to develop a sensitive electrochemical sensor for the determination of 8-OHdG, based on the combination of the extraordinary properties of SWCNTs and the adhesive ability coupled with selective permeation of Nafion. A SWCNTs-Nafion film modified electrode was prepared by drop-coating SWCNTs-Nafion dispersion on the surface of GCE. Here, SWCNTs contributed to enhancing the electrochemical response while Nafion played a crucial role in the renewability and stability of the modified electrode, as well as in alleviating the interferences. In this paper, selection of an adhesive agent, characterization of the SWCNTsNafion nanocomposite film, optimal test conditions, and electrochemical performance and determination of 8-OHdG by developed method are presented. The proposed electrochemical method showed many advantages such as high sensitivity, reproducibility, good selectivity, and simplicity.

\section{Materials and Methods}

2.1. Reagents and Materials. 8-Hydroxy-2'-deoxyguanosine (8-OHdG), deoxyguanosine (dG), Nafion (5 wt\% solution in water and lower aliphatic alcohols), polyethylenimine (PEI, average MW 750000), and streptavidin (SA) were purchased from Sigma-Aldrich (USA). N,N-dimethylformamide (DMF), sodium dodecyl sulfate (SDS) were obtained from Shanghai Reagent Corporation (Shanghai, China). Uricase $(2 \mathrm{U} / \mathrm{mL})$ was obtained from Sigma-Aldrich (USA). High purity single wall carbon nanotubes (SWCNTs, outer diameter $<2 \mathrm{~nm}$, length $=5 \sim 30 \mu \mathrm{m}$, and purity: $>95 \%)$ and short multiwalled carbon nanotubes (MWCNTs, outer diameter: $8 \sim 15 \mathrm{~nm}$, length $=0.5 \sim 2 \mu \mathrm{m}$, and purity: $>95 \%)$ were obtained from Institute of Chengdu Organic Chemicals Co., Ltd. (Chengdu, China). The other reagents were of analytical grade and used without any further purification. Aqueous solutions were all prepared with Millipore Milli-Q water ( $\rho=$ $18.2 \Omega \mathrm{M} \mathrm{cm}$ ).

$0.1 \mathrm{M}$ phosphate buffer saline (PBS, pH 7.40, $0.1 \mathrm{M}$ $\left.\mathrm{NaH}_{2} \mathrm{PO}_{4}+0.1 \mathrm{M} \mathrm{Na} \mathrm{HPO}_{4}+0.1 \mathrm{M} \mathrm{KCl}\right)$ was used as a supporting electrolyte in all measurements.

2.2. Apparatus. All the electrochemical measurements including cyclic voltammetry $(\mathrm{CV})$ and differential pulse 
voltammetry (DPV) were performed on a $\mathrm{CHI} 660 \mathrm{E}$ electrochemical workstation (Shanghai Chenhua Apparatus Co., Ltd., China). The three-electrode system was composed of a bare disk GCE with a diameter of $2 \mathrm{~mm}$ or an electrochemical sensor as the working electrode, a platinum wire as the counter electrode, and $\mathrm{Ag} / \mathrm{AgCl}$ (saturated $\mathrm{KCl}$ ) as the reference electrode. All potentials were in reference to this reference electrode. A digital control ultrasonic instrument (KQ5200DE, 100 W, Kun Shan Ultrasonic Instruments Co., Ltd., China) was used for dispersing CNTs well. A HZ85-2 magnetic stirrer (Beijing Zhongxing Weiye Instrument Co., Ltd., China) was used for stirring the solution during electrochemical measurements.

A Quanta 200 scanning electron microscope (SEM, FEI Company, USA) and a JEM-2100 transmission electron microscope (JEOL, Japan) were used to obtain the microimages of the SWCNTs-Nafion film.

\subsection{Preparation of CNTs Dispersions}

2.3.1. The Pretreatment of CNTs. SWCNTs/MWCNTs were pretreated according to [47] with some modification. Briefly, $500 \mathrm{mg}$ of the pristine SWCNTs/MWCNTs was pretreated in $80 \mathrm{~mL}$ of mixture of concentrated $\mathrm{H}_{2} \mathrm{SO}_{4} / \mathrm{HNO}_{3}(\mathrm{v} / \mathrm{v}, 3: 1)$, ultrasonicated for $4 \mathrm{~h}$, followed by centrifuging and rinsing with water several times until the filtrate was neutral. Finally, the washed CNTs were dried in an oven overnight at $100^{\circ} \mathrm{C}$.

2.3.2. Preparation of the CNTs Dispersion. The SWCNTsDMF/MWCNTs-DMF dispersion was prepared by dispersing $1.0 \mathrm{mg}$ of the pretreated SWCNTs/MWCNTs in $1.0 \mathrm{~mL}$ of DMF with the aid of ultrasonication for 15-30 minutes. The SWCNTs-Nafion dispersion was prepared in the same manner described above, but using $1.0 \mathrm{~mL}$ of $0.5 \%$ Nafion instead. Other SWCNTs-binder (SDS, PEI, SA) dispersions were prepared by dispersing $1.0 \mathrm{mg}$ of the pretreated SWCNTs in $1.0 \mathrm{~mL}$ of $1.0 \mathrm{mg} / \mathrm{mL}$ binder prepared using $1: 1(\mathrm{~V} / \mathrm{V})$ ethanol/water solution.

2.4. Fabrication of Sensor. The GCE was polished manually with a $0.3 \mu \mathrm{m}$ and $0.05 \mu \mathrm{m}$ alumina slurry on a polishing cloth, respectively, followed by ultrasonication in ethanol and water for $3 \mathrm{~min}$, respectively, and was finally rinsed with water and dried with nitrogen steam. The electrochemical sensor was fabricated, typically, by drop-coating $9 \mu \mathrm{L}$ of SWCNTs-Nafion dispersion on the surface of the cleaned GCE, following its exposure to air to be dried. Subsequent modified GCEs were fabricated with the same protocol.

2.5. Electrochemical Measurements. All electrochemical experiments were performed in $0.1 \mathrm{M}$ pH 7.4 PBS at room temperature, $25 \pm 1^{\circ} \mathrm{C}$. CV measurements were conducted to obtain the electrochemical response of 8-OHdG, as well as select adhesive agents after an unstirred accumulation over 5 min.

DPV measurements for the detection for 8-OHdG were performed after the modified electrode had accumulated under magnetic stirring for $9 \mathrm{~min}$. DPV parameters were

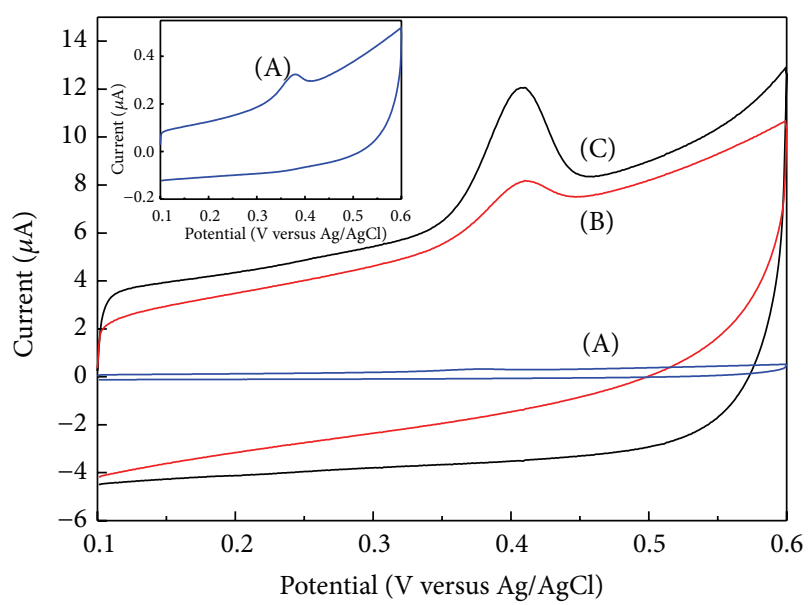

FIGURE 1: Cyclic voltammograms on different electrodes in $0.1 \mathrm{M}$ PBS (pH 7.4) containing $5 \mu \mathrm{M}$ 8-OHdG. (A) Bare GCE, (B) MWCNTs/GCE, and (C) SWCNTs/GCE. Cyclic voltammetric measurements were performed at a scan rate of $50 \mathrm{mV} / \mathrm{s}$ after the electrode was immersed in the tested solution under the condition of $5.0 \mathrm{~min}$ accumulation (unstirring).

selected to attain a pulse amplitude of $50 \mathrm{mV}$, a pulse width of $0.05 \mathrm{~s}$, and a pulse period of $0.5 \mathrm{~s}$.

Recycling the sensors required a renewal process to remove the adsorbed analyte which was performed as follows: the used sensors were immersed in 0.1 M PBS ( $\mathrm{pH}$ 7.4) and then electrochemically treated by successive cyclic voltammetric scanning for 1-3 min in the potential range between +0.1 and $+0.6 \mathrm{~V}$ at a scan rate of $100 \mathrm{mV} \mathrm{s}^{-1}$ until a stable cyclic voltammogram was obtained and, finally, dried with nitrogen steam.

\section{Results and Discussion}

3.1. Electrochemical Behaviors of 8-OHdG on CNTs-Coated GCE. In the preliminary experiments, SWCNTs and MWCNTs were separately dispersed in DMF and then dropcoated on the surface of GCE. Figure 1 shows the cyclic voltammograms of 8-OHdG on bare GCE (curve (A)), MWCNTs/GCE (curve (B)), and SWCNTs/GCE (curve (C)). On bare GCE, the anodic peak potential of 8-OHdG appears at about $+0.38 \mathrm{~V}$. This is in agreement with the reports by $\mathrm{Li}$ et al. [27] and Gutiérrez et al. [30]. On MWCNTs/GCE and SWCNTs/GCE, the anodic peak potentials all positively shift from $+0.38 \mathrm{~V}$ to $+0.41 \mathrm{~V}$. This suggests that MWCNTs and SWCNTs should not have an observed catalytic function for electrochemical oxidation of $8-\mathrm{OHdG}$. It is notable that the oxidation peak currents of 8-OHdG on MWCNTs/GCE and SWCNTs/GCE were significantly enhanced. Compared to the bare GCE, there was about a 20 -fold enhancement in the peak current obtained by subtracting capacitive current from the observed current using MWCNTs/GCE and about a 47-fold enhancement in the peak current obtained by subtracting capacitive current from the observed current using SWCNTs/GCE. This may be attributed to an increase of adsorption amount of 8-OHdG on the surface of the electrodes, and 
the high conductivity of MWCNTs or SWCNTs. This indicates that the enhanced current on SWCNTs/GCE is much larger than that on MWCNTs/GCE. Therefore, SWCNTs were chosen as the modified material in the following experiments.

3.2. Effect of the Adhesive Agents. The common methods to fabricate the electrochemical sensors rely not only on the SWCNTs homogeneous dispersion but also on their ability to adhere onto the surface of the substrate electrode. SWCNTs were often dispersed in organic solvents, such as DMF $[38,39]$, acetonitrile [48], and cyclohexane [49] to obtain a homogeneous suspension for electrochemical sensors. In addition, polymer composites and conjugation chemistry were employed to enhance the adhesion of nanomaterials to the surfaces of the electrodes and to reduce interferers from the complex samples. The choice of a suitable adhesive agent as binder is very important since it decides the physical stability of the SWCNTs modified electrode. If the adhesive agent has an excellent dispersant property, not only will the adhesive force between SWCNTs film and GCE interface be enhanced, but also the uniformity of SWCNTs dispersion will be improved. Typically, from a physical perspective, binding reagents can assist SWCNTs in firmly attaching onto the surface of the substrate electrode to avoid SWCNTs film exfoliation from the substrate electrode. Therefore, in our work, five reagents including Nafion, DMF, SDS, PEI, and SA were chosen as binding reagents. Additionally, since the chosen dispersants are partially solid or sticky fluid, ethanol/water (V/V = 1:1) was used as the solvent. Preparation of SWCNTs dispersion as described in Section 2.3 and the experiments for the investigation of the effect of dispersants on electrochemical properties of SWCNTs/GCE were performed using CV measurements.

At first, the adhesive ability of the binding agents for SWCNTs on the surface of GCE was checked. It was found that both SWCNTs-DMF and SWCNTs-SDS films formed by drop-coating on the surface of GCE were observed to be easily wiped off from the surface of GCE. This is attributed to the fact that both DMF and SDS have a low adhesive ability. It was found that the electrodes modified with SWCNTsNafion, SWCNTs-PEI, and SWCNTs-SA films were observed to be firmly attached to the surface of the GCE. Figure 2 shows the voltammograms of 8-OHdG at SWCNTs-Nafion (curve (A)), SWCNTs-PEI (curve (B)), SWCNTs-SA (curve $(C)$ ), and SWCNTs (curve (D), ethanol/water $\mathrm{V} / \mathrm{V}=1: 1$ as solvent) film modified GCE. Comparing curve (A) with (D), the oxidation peak current increases from $24.23 \mu \mathrm{A}$ to $54.15 \mu \mathrm{A}$. This indicates that $8-\mathrm{OHdG}$ can be accumulated in SWCNTs-Nafion film. Comparing curve (B) with (D), the anodic peak potential negatively shifts from $0.41 \mathrm{~V}$ to $0.32 \mathrm{~V}$, indicating that PEI could overcome the overpotential of the oxidation of 8-OHdG. This is consistent with the report by Gutiérrez et al. [30]. Comparing curve (C) with (D), the oxidation peak current slightly decreases. This indicates that SA could not improve the oxidation of 8-OHdG. In order to obtain the high sensitivity and stability required, Nafion was selected as the binding reagent in subsequent experiments.

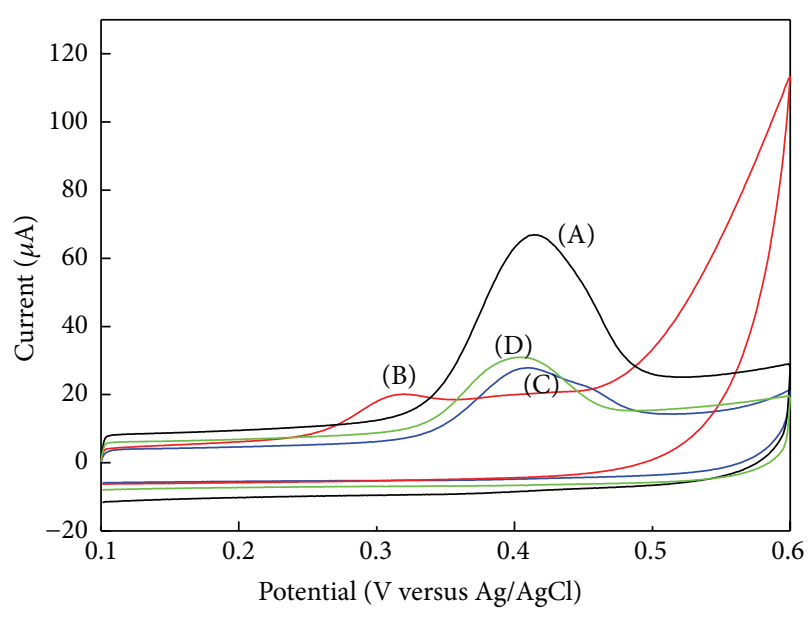

FIGURE 2: Cyclic voltammograms on different SWCNTs film modified electrodes in $0.1 \mathrm{M}$ PBS ( $\mathrm{pH} 7.4$ ) containing $50 \mu \mathrm{M} \mathrm{8-}$ $\mathrm{OHdG}$ with a scan rate of $50 \mathrm{mV} / \mathrm{s}$. (A) SWCNTs-Nafion/GCE, (B) SWCNTs-PEI/GCE, (C) SWCNTs-SA/GCE, and (D) SWCNTs/GCE. Cyclic voltammetric measurements conditions are the same as in Figure 1.

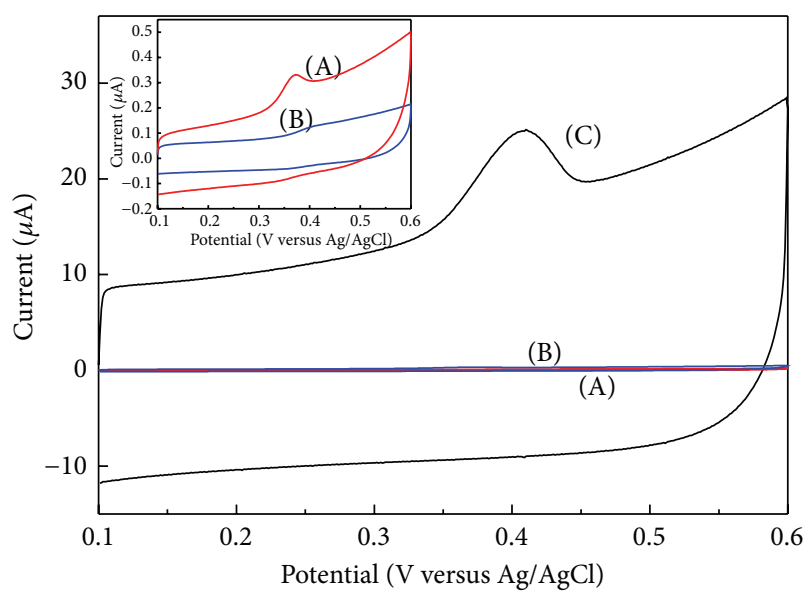

FIGURE 3: Cyclic voltammograms on different electrodes in $0.1 \mathrm{M}$ PBS (pH 7.4) containing $5 \mu \mathrm{M}$ 8-OHdG. (A) Bare GCE, (B) Nafion/GCE, and (C) SWCNTs-Nafion/GCE. Cyclic voltammetric measurements conditions are the same as in Figure 1.

To investigate the functions of Nafion and SWCNTs, $\mathrm{CV}$ measurements are performed on 8-OHdG with three different electrodes including bare GCE, Nafion/GCE, and SWCNTs-Nafion/GCE, as showed in Figure 3. The results showed that the oxidation peak current of the bare GCE (curve (A)) was higher than that of Nafion/GCE (curve (B)). This is attributed to the fact that the diffusion coefficient of 8-OHdG is lower in the Nafion polymer film than in aqueous solution. This indicates that the Nafion polymer film slightly blocks the electron transfer between the surface of GCE and the electrolyte. The oxidation peak current of SWCNTs-Nafion/GCE $(9.30 \mu \mathrm{A}$ ) (curve (C)) was much higher than that of bare GCE $(0.128 \mu \mathrm{A})$, indicating that SWCNTs-Nafion/GCE can enhance the peak current about 


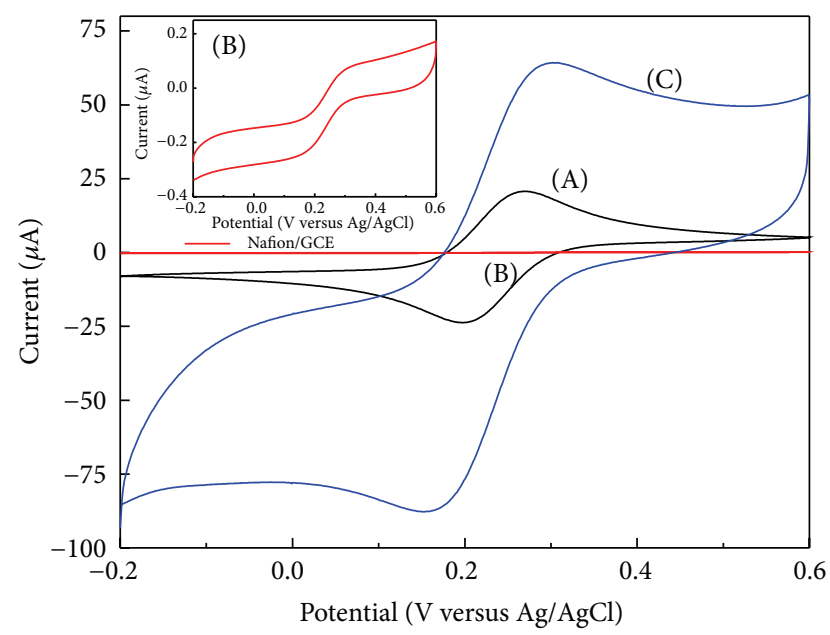

Figure 4: Cyclic voltammograms on different electrodes at a scan rate of $50 \mathrm{mV} / \mathrm{s}$ in $0.1 \mathrm{M}$ PBS (pH 7.4) containing $5.0 \mathrm{mM}$ $\mathrm{K}_{3} \mathrm{Fe}(\mathrm{CN})_{6}-5.0 \mathrm{mM} \mathrm{K}_{4}\left[\mathrm{Fe}(\mathrm{CN})_{6}\right]$. (A) Bare GCE, (B) Nafion/GCE, and (C) SWCNTs-Nafion/GCE.

73-fold when compared to a bare GCE. This may be attributed to the unique microstructure characteristics inherent to the special SWCNTs and Nafion.

To obtain information on the SWCNTs-Nafion film, a potassium ferricyanide system was used as an electrochemical redox probe. The large differences in cyclic voltammograms of $\left[\mathrm{Fe}(\mathrm{CN})_{6}\right]^{3-/ 4-}$ were clearly observed for three different electrodes including bare GCE, Nafion/GCE, and SWCNTs-Nafion/GCE from Figure 4. For the bare GCE (curve (A)), a well-defined cyclic voltammogram can be seen, and the anodic peak current $\left(i_{\text {pa }}\right)$ and cathodic peak current $\left(i_{\mathrm{pc}}\right)$ were $25.2 \mu \mathrm{A}$ and $-25.5 \mu \mathrm{A}$, respectively, with a peak potential separation $(\triangle \mathrm{Ep})$ of $0.065 \mathrm{~V}$. After the GCE was modified with Nafion (curve (B)), the redox peak currents were greatly reduced. This can be ascribed to the fact that negatively charged Nafion films partly hinder the diffusion of $\left[\mathrm{Fe}(\mathrm{CN})_{6}\right]^{3-/ 4-}$ through the film, which have been illustrated in some previous reports $[45,50] . i_{\mathrm{pa}}$ and $i_{\mathrm{pc}}$ for the SWCNTsNafion/GCE (curve (C)) were $69.2 \mu \mathrm{A}$ and $-70.5 \mu \mathrm{A}$, respectively, with $\triangle \mathrm{Ep}$ of $0.15 \mathrm{~V}$. The introduction of SWCNTs with Nafion films resulted in a considerable increase of the peak currents, indicating that SWCNTs provided the conducting bridges for the electron transfer of $\left[\mathrm{Fe}(\mathrm{CN})_{6}\right]^{3-/ 4}[50]$. This confirms that the combination of SWCNTs and Nafion film can increase the currents of the analytes.

To obtain the microstructure information of the SWCNTs-Nafion dispersion, scanning electron microscopy (SEM) in combination with transmission electron microscopy (TEM) was used to characterize the micromorphology of the SWCNTs-Nafion dispersion. As displayed in Figure 5(a), a uniform and homogeneous distribution of SWCNTs-Nafion film was formed. Typical TEM images in Figure 5(b) displayed a scattered distribution of welldispersed SWCNT clusters. The results indicate that Nafion can disperse SWCNTs well to form a uniform and homogeneous distribution of SWCNTs-Nafion film on GCE.
Additionally, the effects of scan rates on the electrochemical oxidation of 8-OHdG on SWCNTs-Nafion/GCE were investigated. The result was showed in Figure 6. It can be seen that the oxidation peak currents increased with the up of scan rate (Figure 6(a)) and were proportional to the scan rate (5 500 mV/s) (Figure 6(b)), relying on the linear regression equation: $i_{p}(\mu \mathrm{A})=0.2391+0.7318 \mathrm{v}(\mathrm{mV} / \mathrm{s})(R=0.9996)$. This indicates that the electrochemical oxidation process of 8-OHdG on SWCNTs-Nafion/GCE was a surface-defined controlled process.

3.3. Effect of Modification Volume of SWCNTs-Nafion Dispersion and Accumulation Time. We found that stirring of the tested solution during accumulation time when the electrochemical sensors were immersed in the solution affected the peak current. Cyclic voltammetric measurements were performed after different accumulation conditions. Figure 7(a) shows cyclic voltammograms obtained on the sensors after an accumulation time of $5 \mathrm{~min}$ without stirring (curve (A)) and with a constant stirring (curve (B)). The result shows that stirring the tested solution can increase the peak current of 8OHdG about 2.7-fold when compared to an unstirred case.

As expected, modification volume of SWCNTs-Nafion dispersion decides the amount of the SWCNTs-Nafion on the GCE and further affects the sensitivity. Thus, the effect of the modification volume of SWCNTs-Nafion on the peak current was checked using a fixed concentration of SWCNTs-Nafion $(1.0 \mathrm{mg} / \mathrm{mL})$ and stirring for $5 \mathrm{~min}$. The result in Figure 7(b) shows the dependence of the peak current on the volume of SWCNTs-Nafion dispersion. From Figure 7(b), it can be seen that the peak currents linearly increase from 1 to $7 \mu \mathrm{L}$. This is attributed to the fact that the amount of $8-\mathrm{OHdG}$ in SWCNTs-Nafion film on the electrode increases. And then, the peak current reaches a stable platform between $7 \mu \mathrm{L}$ and $11 \mu \mathrm{L}$. When the volume is higher than $11 \mu \mathrm{L}$, the signal declines. This can be ascribed to the formation of a thicker film, which increases the resistance of 8-OHdG from the bulk solution to the surface of the electrode. Therefore, the volume of $9 \mu \mathrm{L}$ was chosen as the optimum volume.

Effect of accumulation time on the peak current was checked under moderate stirring with a magnetic stirrer, as shown in Figure 7(c). The peak current linearly increases from 1 to $7 \mathrm{~min}$. This is attributed to the fact that the amount of 8-OHdG in SWCNTs-Nafion film on the electrode increases. And then, the peak current reaches a stable plateau between 7 and $13 \mathrm{~min}$. This is attributed to the fact that the amount of 8-OHdG to be concentrated in the SWCNTsNafion film reaches a saturation state of adsorption, as expected for a process under adsorptive control, which is consistent with the inference above. Therefore, the optimal accumulation time of $9 \mathrm{~min}$ was chosen for further experiments.

3.4. DPV Determination of $8-O H d G$. Differential pulse voltammetry (DPV) is a highly sensitive and selective tool for quantitative analysis when compared to the linear scan voltammetry. Therefore, the electrochemical determination of $8-\mathrm{OHdG}$ was examined using DPV at the fabricated 


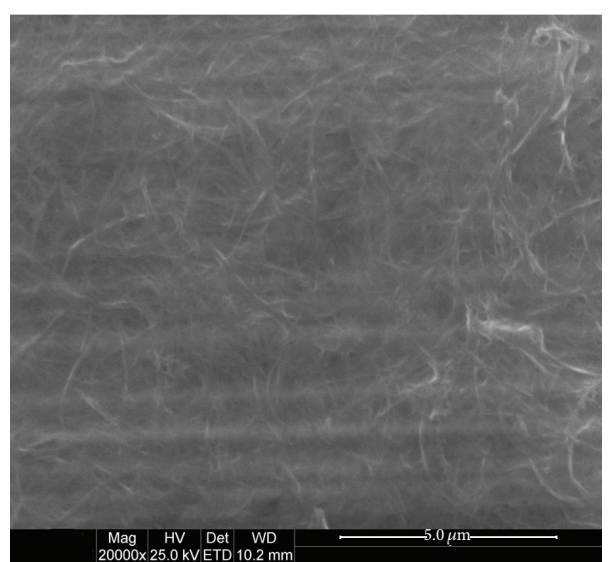

(a)

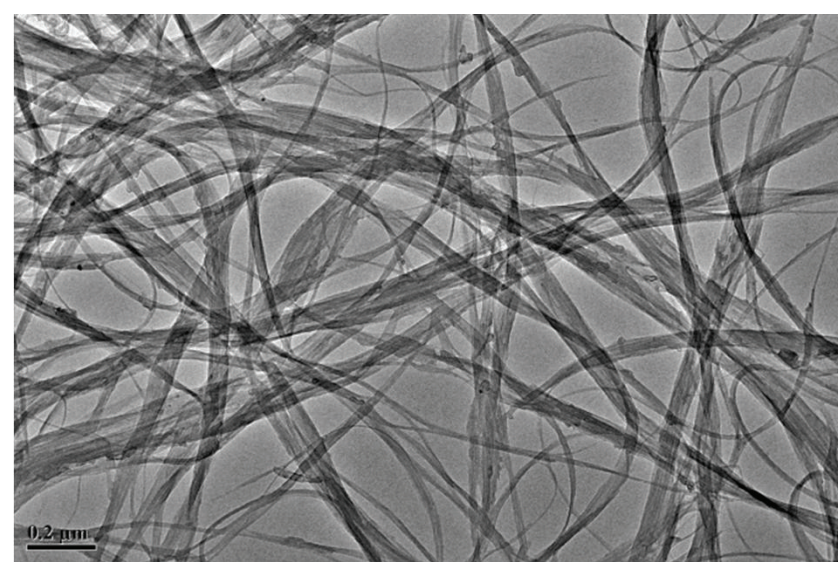

(b)

Figure 5: (a) SEM image of SWCNTs-Nafion film. Acceleration voltage, 25kV. Magnification 20,000x (scale bar = 500 nm). (b) TEM micrograph of SWCNTs-Nafion film (scale bar $=200 \mathrm{~nm})$.

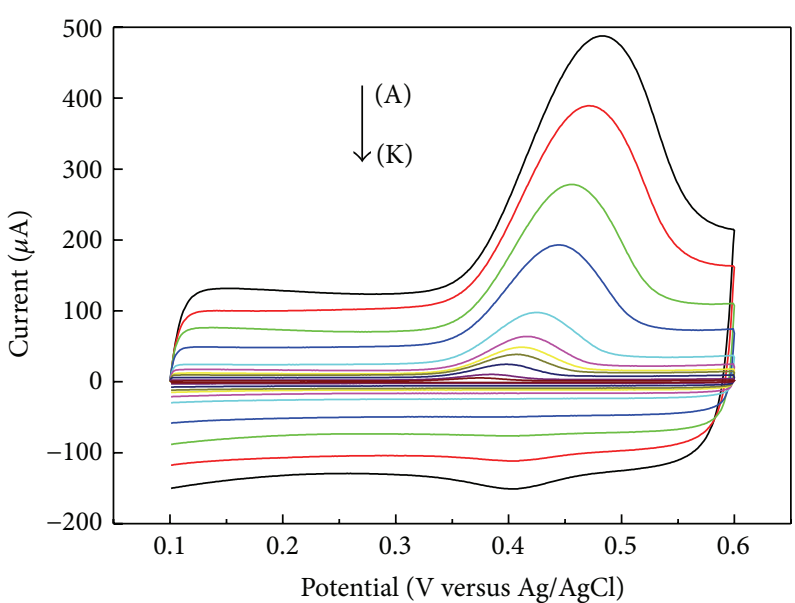

$\begin{array}{ll}\text { (A): } 500 \mathrm{mV} / \mathrm{s} & \text { (G): } 50 \mathrm{mV} / \mathrm{s} \\ \text { (B): } 400 \mathrm{mV} / \mathrm{s} & -(\mathrm{H}): 40 \mathrm{mV} / \mathrm{s} \\ \text { (C): } 300 \mathrm{mV} / \mathrm{s} & -(\mathrm{I}): 25 \mathrm{mV} / \mathrm{s} \\ \text { (D): } 200 \mathrm{mV} / \mathrm{s} & -(\mathrm{J}): 10 \mathrm{mV} / \mathrm{s} \\ \text { (E): } 100 \mathrm{mV} / \mathrm{s} & -(\mathrm{K}): 5 \mathrm{mV} / \mathrm{s} \\ \text { (F): } 70 \mathrm{mV} / \mathrm{s} & \end{array}$

(a)

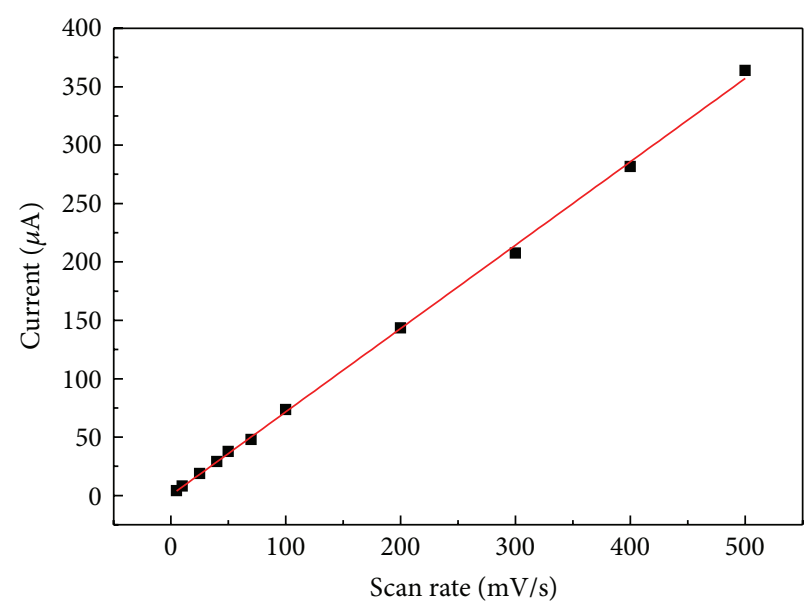

(b)

FIGURE 6: (a) Cyclic voltammograms in $0.1 \mathrm{M}$ PBS (pH 7.4) containing $5 \mu \mathrm{M}$ 8-OHdG at different scan rates from $5 \mathrm{mV} / \mathrm{s}$ to $500 \mathrm{mV} / \mathrm{s}$ on the SWCNTs-Nafion/GCE. (b) Dependence of the peak current on the scan rates from $5 \mathrm{mV} / \mathrm{s}$ to $500 \mathrm{mV} / \mathrm{s}$.

sensors under the stated optimal conditions. Figure 8(a) shows the DPV response curves of 8-OHdG in the concentration range of 0 to $8.75 \mu \mathrm{M}$. Figure $8(\mathrm{~b})$ shows the corresponding dependence of the oxidation currents on the concentration of 8-OHdG. The peak currents are proportional to the concentration of 8-OHdG over two concentration intervals: $0.03 \sim 1.25 \mu \mathrm{M}$ (line (A)) and 1.25 8.75 $\mu \mathrm{M}$ (line (B)). The linear regression equations are expressed as follows: $i_{p}(\mu \mathrm{A})=$ $0.233+16.731 C(\mu \mathrm{M})(R=0.9995,0.03 \sim 1.25 \mu \mathrm{M})$ and $i_{p}$ $(\mu \mathrm{A})=10.030+9.229 \mathrm{C}(\mu \mathrm{M})(R=0.9987,1.25 \sim 8.75 \mu \mathrm{M})$. The detection limit $(\mathrm{S} / \mathrm{N}=3)$ was estimated to be $8.0 \mathrm{nM}$. The slopes of the two linear ranges are $16.731 \mu \mathrm{A} / \mu \mathrm{M}$ and
$9.229 \mu \mathrm{A} / \mu \mathrm{M}$, respectively. The detection limit in this work $(8.0 \mathrm{nM})$ is much lower than that reported using poly(3methylthiophene) modified GCE $(0.10 \mu \mathrm{M})$ [27] and MWCNTs/PEI modified electrode $(0.10 \mu \mathrm{M})$ [30]. The slope of the linear range at low concentrations in this work is much higher than that reported using poly(3-methylthiophene) modified GCE $(0.361 \mu \mathrm{A} / \mu \mathrm{M}, \Phi=3 \mathrm{~mm})$ [27] and using MWCNTs/PEI modified electrodes $(2.67 \mu \mathrm{A} / \mu \mathrm{M}, \Phi=3 \mathrm{~mm})$ [30]. However, the detection limit in this work is only slightly higher than that reported using electrochemically graphene/Nafion nanocomposite film modified GCE (linear range is $0.07 \sim 3.64 \mu \mathrm{M}$ with the detection limit of $1.12 \mathrm{nM}$ ) 


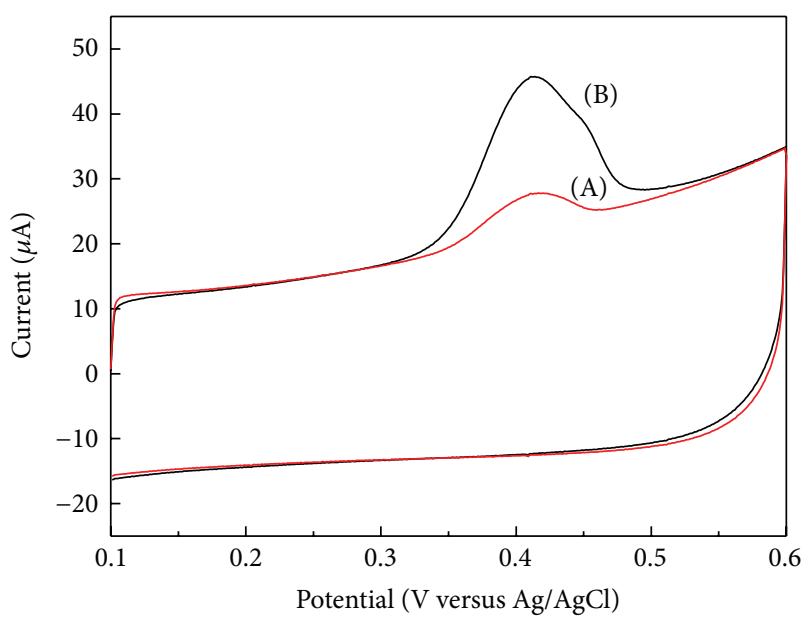

(a)

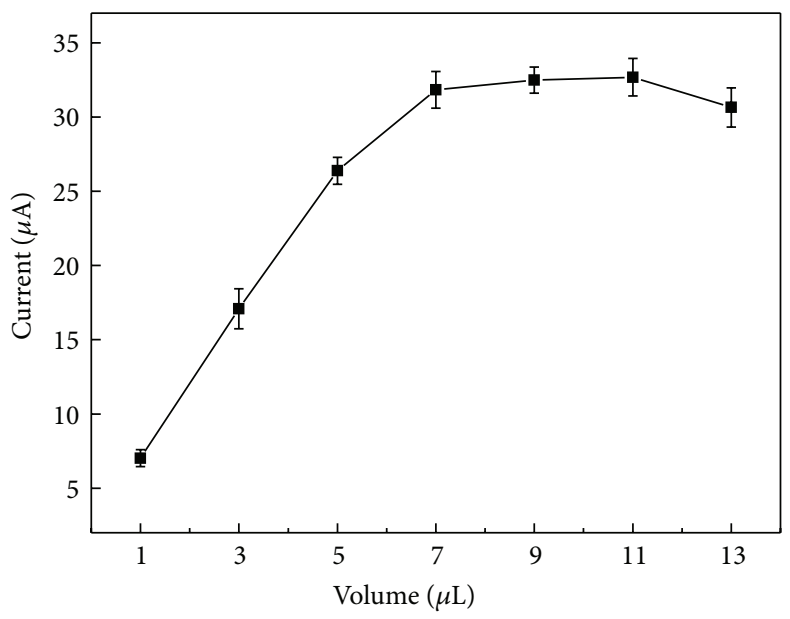

(b)

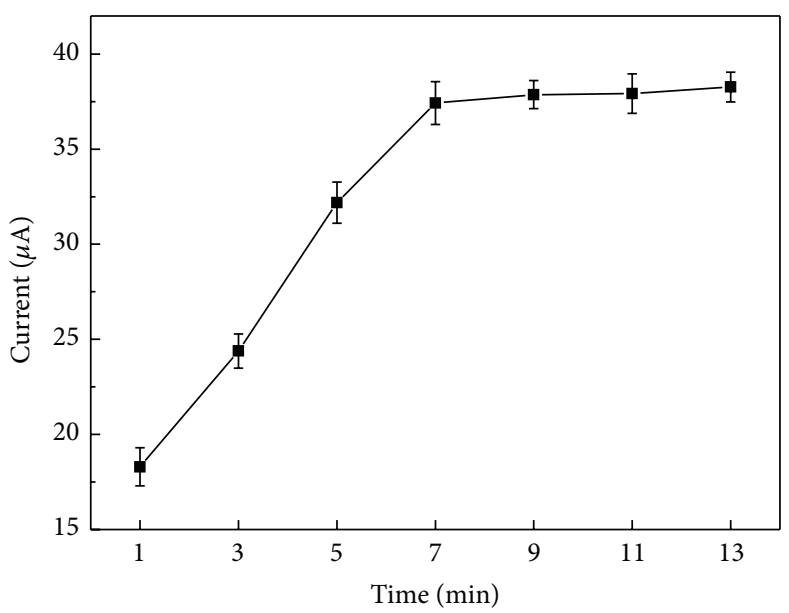

(c)

Figure 7: (a) Cyclic voltammograms on SWCNTs-Nafion/GCE under different accumulation conditions for 5 min. (A) Without stirring. (B) With stirring. (b) Dependence of the peak current on the volume of SWCNTs-Nafion dispersion. (c) Dependence of the peak current on the accumulation time at SWCNTs-Nafion/GCE. Cyclic voltammetric measurements were performed in pH 7.4 PBS solution containing $5 \mu \mathrm{M}$ 8 -OHdG at a scan rate of $50 \mathrm{mV} / \mathrm{s}$.

[28], in which it was required that graphene be synthesized electrochemically from graphite oxide. A lower detection limit of the proposed method is, therefore, feasible.

The reproducibility of the sensors for quantification of 8 -OHdG was evaluated by testing 7 sensors fabricated. The results showed that the relative standard deviation (RSD) was $6.1 \%$. This indicates that the Nafion-SWCNTs/GCE fabrication process has a good level of reproducibility.

The renewability of the sensors is an important issue in the application of the sensors. Although the modification process proposed in this work is simple, the renewable ability of the sensors was also checked. After each DPV determination, the sensor was renewed as described in Section 2.5. The results showed that the RSD was 3.9\% for one sensor in 7 repeat measurements. A satisfactory renewability of the modified electrodes is, therefore, evident.

3.5. Specificity Tests. Uric acid (UA) and ascorbic acid (AA) are generally considered as the main interferers in the electrochemical determination of $8-\mathrm{OHdG}$ since they are electroactive coexistent compounds. Therefore, the influence of UA and AA on the DPV peak current of 8-OHdG was examined using fabricated sensors. In the case of our study, the oxidation peak potential of AA, UA, and 8OHdG appeared at about $-0.10 \mathrm{~V},+0.30 \mathrm{~V}$, and $+0.38 \mathrm{~V}$, respectively. The oxidation peak current of $0.5 \mu \mathrm{M} 8-\mathrm{OHdG}$ only decreased $1.3 \%$ in the presence of $0.25 \mathrm{mM}$ AA (500fold of $8-\mathrm{OHdG}$ ). This indicates that AA caused a negligible response. The oxidation peak current of $8-\mathrm{OHdG}$ only decreased $5.0 \%$ in the presence of $0.05 \mathrm{mM}$ UA (100-fold of 8-OHdG). This indicates that UA did not cause a significant response. When the concentration of UA was increased to $0.1 \mathrm{mM}$ (200-fold) and $0.25 \mathrm{mM}$ (500-fold), the oxidation peak currents of 8 -OHdG were decreased by $6.7 \%$ and $10 \%$, respectively. The high selectivity of the developed method in this work may be attributed to the fact that the negatively charged SWCNTs-Nafion film repels AA and UA anions and provides a transport channel only for 8-OHdG cations, 

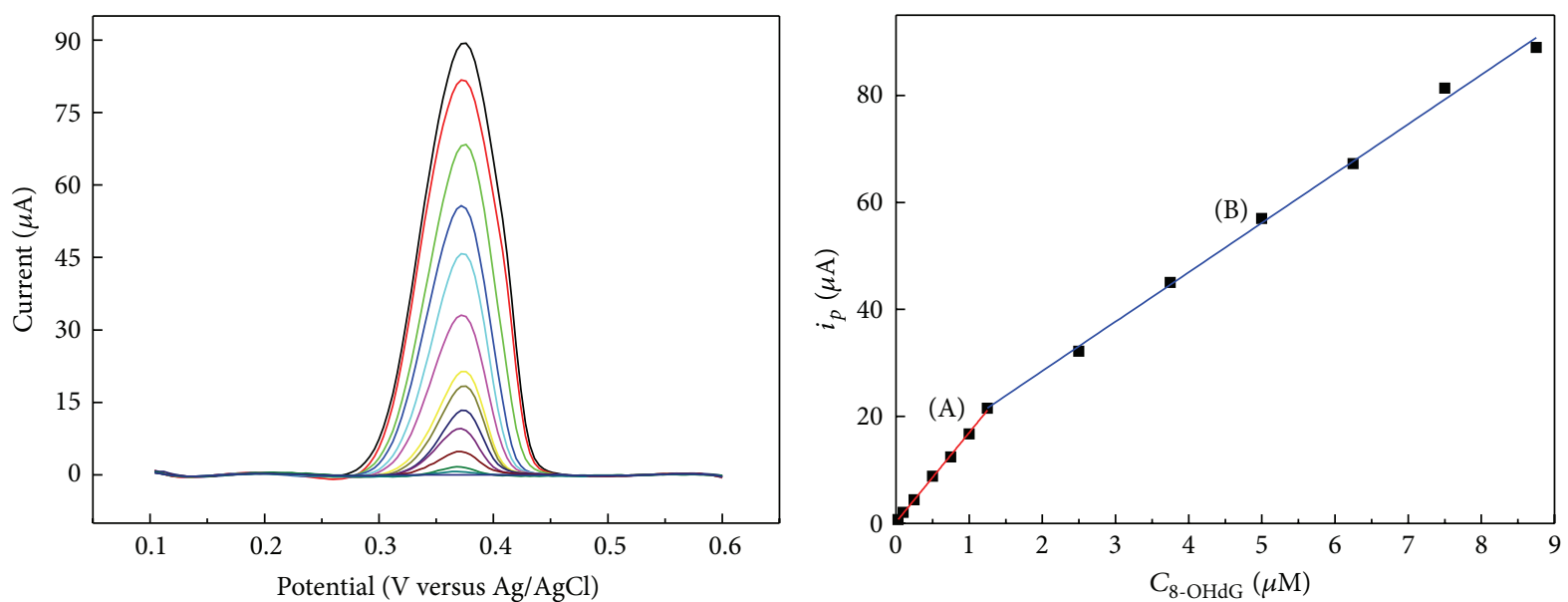

$\begin{array}{ll}- \text { (A): }: 8.75 \mu \mathrm{M} & -(\mathrm{H}): 1.0 \mu \mathrm{M} \\ \text { (B): }: .5 \mu \mathrm{M} & -(\mathrm{I}): 0.75 \mu \mathrm{M} \\ \text { (C): } 6.25 \mu \mathrm{M} & -(\mathrm{J}): 0.5 \mu \mathrm{M} \\ \text { (D): }: 5.0 \mu \mathrm{M} & -(\mathrm{K}): 0.25 \mu \mathrm{M} \\ \text { (E): }: 35 \mu \mathrm{M} & -(\mathrm{L}): 0.1 \mu \mathrm{M} \\ \text { (F): } 2.5 \mu \mathrm{M} & -(\mathrm{M}): 0.03 \mu \mathrm{M} \\ \text { (G): } 1.25 \mu \mathrm{M} & -(\mathrm{N}): 0.0 \mu \mathrm{M}\end{array}$

(a) (b)

FIGURE 8: (a) Differential pulse voltammograms of different concentration of 8-OHdG with the subtraction of background current on SWCNTs-Nafion/GCE. (b) Calibration curve of the concentration of 8-OHdG.

since in $\mathrm{pH} 7.4$ PBS 8-OHdG $\left(\mathrm{pK}_{a 1}=8.6\right.$ and $\left.\mathrm{pK}_{a 2}=11.7\right)$ exists in cationic form, while $\mathrm{AA}\left(\mathrm{pK}_{a}=4.17\right)$ and UA $\left(\mathrm{pK}_{a}=5.7\right)$ are anionic. Therefore, the prepared SWCNTsNafion/GCE greatly improved the selectivity towards 8OHdG. Additionally, deoxyguanosine $(\mathrm{dG})$, which is the oxidation precursor of $8-\mathrm{OHdG}$, was also examined as an interference for evaluating oxidative DNA damage. It was found that, in the case of optimal conditions as in this work, the oxidation peak potential of $\mathrm{dG}$ appeared at about $+0.92 \mathrm{~V}$ while the presence of high concentration of dG $(3 \mu \mathrm{M}, 6$-fold of $8-\mathrm{OHdG}$ ) caused a $10 \%$ decrease of oxidation peak of 8 OHdG. It can be seen that increased concentration of dG led to a greater decline of peak of $8-\mathrm{OHdG}$ (see Table 1). This may be explained by the fact that $\mathrm{dG}$ clogged the mass transferring pores in Nafion film on GCE.

3.6. Analysis of Spiked Urine Samples. The application of the fabricated sensors was evaluated using a spiked recovery of urine samples. The urine samples from healthy volunteers were centrifuged at $5000 \mathrm{rpm}$ for $10 \mathrm{~min}$ to remove precipitation. The supernatant was diluted with $0.10 \mathrm{M} \mathrm{pH} 7.4$ PBS at the dilution ratio of $1: 10$ and $1: 1$, respectively. The results showed that the spiked recovery of $95.0 \% \sim 103.6 \%$ was obtained with 10 -fold-diluted samples $(n=3)$ for 8 OHdG (Table 2). For the onefold-diluted samples, $0.6 \mathrm{mg} / \mathrm{mL}$ uricase can effectively eliminate the interference of UA. In the presence of $0.6 \mathrm{mg} / \mathrm{mL}$ uricase, a linear regression equation $\left(i_{p}(\mu \mathrm{A})=0.452+8.805 C(\mu \mathrm{M})\right)$ was obtained in the range of $0.1 \mu \mathrm{M} \sim 1.5 \mu \mathrm{M}$ with a correlation coefficient of 0.9991 for addition of $8-\mathrm{OHdG}$ into onefold-diluted samples. Based on
TABLE 1: Current data of 8-OHdG obtained from DPV measurements before and after adding a certain concentration of dG.

\begin{tabular}{lcc}
\hline$C_{8 \text {-OHdG }}: C_{\mathrm{dG}}$ & $\begin{array}{c}\mathrm{ip}_{8 \text {-OHdG }} / \mu \mathrm{A} \\
\text { (after added dG) }\end{array}$ & $\begin{array}{c}\text { The decline of } \\
\text { current }\end{array}$ \\
\hline $1: 2$ & $8.15 \pm 0.06$ & $5.2 \%$ \\
$1: 4$ & $7.90 \pm 0.05$ & $8.1 \%$ \\
$1: 6$ & $7.74 \pm 0.10$ & $10 \%$ \\
$1: 8$ & $7.23 \pm 0.11$ & $15.9 \%$ \\
$1: 10$ & $6.73 \pm 0.07$ & $21.7 \%$ \\
\hline
\end{tabular}

A fixed concentration of 8-OHdG $\left(C_{8-\mathrm{OHdG}}\right)$ is $0.5 \mu \mathrm{M}$, and the corresponding peak current $\left(\mathrm{ip}_{8 \text {-OHdG }}\right)$ is $8.60 \pm 0.12 \mu \mathrm{A}$. $C_{8 \text {-OHdG }}: C_{\mathrm{dG}}$ and the peak currents of $8-\mathrm{OHdG}$ after added dG are listed above. The decline of the currents was calculated according to $\mathrm{ip}_{8-\mathrm{OHdG}}$ before and after added dG as listed above. The results represent the mean \pm standard deviation (SD), calculated from three independent experiments $(n=3)$.

this equation, recovery for $8-\mathrm{OHdG}$ in simulated patient urine samples [51] was tested. The results are listed in Table 2. The satisfactory recovery for $8-\mathrm{OHdG}$ was obtained. This indicates that the developed method may provide a potential application for the estimation of 8-OHdG levels in urine from patients suffering from 8-OHdG-related diseases.

\section{Conclusion}

A novel electrochemical sensor incorporating a SWCNTsNafion composite film coated on GCE for the determination of 8-OHdG was developed. This electrochemical sensor was extremely sensitive, highly selective, and sufficiently accurate 
TABLE 2: Recovery results for 8-OHdG from different dilution urine samples.

\begin{tabular}{lccc}
\hline $\begin{array}{l}\text { Sample } \\
\text { dilution }\end{array}$ & $\begin{array}{c}\text { Added } \\
(\mu \mathrm{M})\end{array}$ & Found $(\mu \mathrm{M})$ & $\begin{array}{c}\text { Recovery } \\
(\%)\end{array}$ \\
\hline & 0.05 & $0.0475 \pm 0.03$ & 95.0 \\
$1: 10^{\mathrm{a}}$ & 0.15 & $0.152 \pm 0.03$ & 101.0 \\
& 0.50 & $0.518 \pm 0.05$ & 103.6 \\
\hline & 0.20 & $0.191 \pm 0.03$ & 95.5 \\
$1: 1^{\mathrm{a}}$ & 0.30 & $0.286 \pm 0.04$ & 95.3 \\
& 0.40 & $0.413 \pm 0.02$ & 103.3 \\
\hline
\end{tabular}

${ }^{a}$ The results represent the mean \pm standard deviation (SD) from three independent experiments $(n=3)$.

towards 8-OHdG detection and quantification. Examinations on the regeneration ability and the spiked recovery of the sensors for urine samples also gave satisfactory results. This work demonstrates that SWCNTs-Nafion films can improve the sensitivity, selectivity, reproducibility, and stability of the electrochemical sensors for the determination of 8-OHdG, thereby making it an ideal candidate for electrochemical detection of 8 -OHdG. The research work is going on to improve the selectivity by minimizing interferers from other electrochemical activated molecules, such as dG and UA. Further, the highly sensitive system will be used to quantitatively assess oxidative DNA damage induced by various nonmaterials' exposure.

\section{Conflict of Interests}

The authors declare that there is no conflict of interests regarding the publication of this paper.

\section{Acknowledgments}

Financial supports from the National Science Foundation of China (nos. 21328501, 21375084, 21275095, and 21027007) and the Natural Science Basic Research Plan in Shaanxi Province of China (no. 2013KJXX-73) are gratefully acknowledged.

\section{References}

[1] H. Kasai, "Analysis of a form of oxidative DNA damage, 8hydroxy-2'-deoxyguanosine, as a marker of cellular oxidative stress during carcinogenesis," Mutation Research, vol. 387, no. 3, pp. 147-163, 1997.

[2] L. L. Wu, C.-C. Chiou, P.-Y. Chang, and J. T. Wu, "Urinary 8OHdG: a marker of oxidative stress to DNA and a risk factor for cancer, atherosclerosis and diabetics," Clinica Chimica Acta, vol. 339, no. 1-2, pp. 1-9, 2004.

[3] A. Valavanidis, T. Vlachogianni, and C. Fiotakis, "8-Hydroxy$2^{\prime}$-deoxyguanosine (8-OHdG): a critical biomarker of oxidative stress and carcinogenesis," Journal of Environmental Science and Health-Part C: Environmental Carcinogenesis and Ecotoxicology Reviews, vol. 27, no. 2, pp. 120-139, 2009.

[4] K. Bialkowski, R. Kowara, W. Windorbska, and R. Olinski, "8oxo- 2 '-deoxyguanosine level in lymphocytes DNA of cancer patients undergoing radiotherapy," Cancer Letters, vol. 99, no. 1, pp. 93-97, 1996.

[5] M. Murata, M. Mizutani, S. Oikawa, Y. Hiraku, and S. Kawanishi, "Oxidative DNA damage by hyperglycemia-related aldehydes and its marked enhancement by hydrogen peroxide," FEBS Letters, vol. 554, no. 1-2, pp. 138-142, 2003.

[6] T. Nishikawa, T. Sasahara, S. Kiritoshi et al., "Evaluation of urinary 8-hydroxydeoxy-guanosine as a novel biomarker of macrovascular complications in type 2 diabetes," Diabetes Care, vol. 26, no. 5, pp. 1507-1512, 2003.

[7] K. Tamae, K. Kawai, S. Yamasaki et al., "Effect of age, smoking and other lifestyle factors on urinary 7-methylguanine and 8hydroxydeoxyguanosine," Cancer Science, vol. 100, no. 4, pp. 715-721, 2009.

[8] A. Kikuchi, A. Takeda, H. Onodera et al., "Systemic increase of oxidative nucleic acid damage in Parkinson's disease and multiple system atrophy," Neurobiology of Disease, vol. 9, no. 2, pp. 244-248, 2002.

[9] C.-M. Chen, J.-L. Liu, Y.-R. Wu et al., "Increased oxidative damage in peripheral blood correlates with severity of Parkinson's disease," Neurobiology of Disease, vol. 33, no. 3, pp. 429-435, 2009.

[10] S. Prabhulkar and C.-Z. Li, "Assessment of oxidative DNA damage and repair at single cellular level via real-time monitoring of 8-OHdG biomarker," Biosensors and Bioelectronics, vol. 26, no. 4, pp. 1743-1749, 2010.

[11] X. Zhu, E. Hondroulis, W. Liu, and C.-Z. Li, "Biosensing approaches for rapid genotoxicity and cytotoxicity assays upon nanomaterial exposure," Small, vol. 9, no. 9-10, pp. 1821-1830, 2013.

[12] H. Kasai, N. Iwamoto-Tanaka, T. Miyamoto et al., "Life style and urinary 8-hydroxydeoxyguanosine, a marker of oxidative DNA damage: effects of exercise, working conditions, meat intake, body mass index, and smoking," Japanese Journal of Cancer Research, vol. 92, no. 1, pp. 9-15, 2001.

[13] S. Koide, Y. Kinoshita, N. Ito, J. Kimura, K. Yokoyama, and I. Karube, "Determination of human serum 8-hydroxy-2' deoxyguanosine (8-OHdG) by HPLC-ECD combined with solid phase extraction (SPE)," Journal of Chromatography B, vol. 878, no. 23, pp. 2163-2167, 2010.

[14] Y. Inaba, S. Koide, K. Yokoyama, and I. Karube, "Development of urinary 8-hydroxy-2' -deoxyguanosine (8-OHdG) measurement method combined with SPE," Journal of Chromatographic Science, vol. 49, no. 4, pp. 303-309, 2011.

[15] H.-S. Lin, A. M. Jenner, C. N. Ong, S. H. Huang, M. Whiteman, and B. Halliwell, "A high-throughput and sensitive methodology for the quantification of urinary 8-hydroxy-2' deoxyguanosine: measurement with gas chromatography-mass spectrometry after single solid-phase extraction," Biochemical Journal, vol. 380, no. 2, pp. 541-548, 2004.

[16] S. Mei, Q. Yao, C. Wu, and G. Xu, "Determination of urinary 8-hydroxy-2'-deoxyguanosine by two approaches-capillary electrophoresis and GC/MS: an assay for in vivo oxidative DNA damage in cancer patients," Journal of Chromatography B: Analytical Technologies in the Biomedical and Life Sciences, vol. 827, no. 1, pp. 83-87, 2005.

[17] A. Weimann, D. Belling, and H. E. Poulsen, "Measurement of 8oxo- 2 '-deoxyguanosine and 8-oxo- 2 '-deoxyadenosine in DNA and human urine by high performance liquid chromatographyelectrospray tandem mass spectrometry," Free Radical Biology and Medicine, vol. 30, no. 7, pp. 757-764, 2001. 
[18] M. Harri, H. Kasai, T. Mori, J. Tornaeus, K. Savela, and K. Peltonen, "Analysis of 8-hydroxy-2'-deoxyguanosine in urine using high-performance liquid chromatography-electrospray tandem mass spectrometry," Journal of Chromatography B, vol. 853, no. 1-2, pp. 242-246, 2007.

[19] B. Crow, M. Bishop, K. Kovalcik, D. Norton, J. George, and J. A. Bralley, "A simple and cost effective method for the quantification of 8-hydroxy-2'-deoxyguanosine from urine using liquid chromatography tandem mass spectrometry," Biomedical Chromatography, vol. 22, no. 4, pp. 394-401, 2008.

[20] P. R. Patel, R. J. Bevan, N. Mistry, and J. Lunec, "Evidence of oligonucleotides containing 8-hydroxy-2'-deoxyguanosine in human urine," Free Radical Biology and Medicine, vol. 42, no. 4, pp. 552-558, 2007.

[21] K. Kaneko, T. Kimata, S. Tsuji et al., "Measurement of urinary 8-oxo-7,8-dihydro-2-deoxyguanosine in a novel point-of-care testing device to assess oxidative stress in children," Clinica Chimica Acta, vol. 413, no. 23-24, pp. 1822-1826, 2012.

[22] Q.-H. Yao, S.-R. Mei, Q.-F. Weng et al., "Determination of urinary oxidative DNA damage marker 8-hydroxy-2' deoxyguanosine and the association with cigarette smoking," Talanta, vol. 63, no. 3, pp. 617-623, 2004.

[23] M.-J. Li, J.-B. Zhang, W.-L. Li, Q.-C. Chu, and J.-N. Ye, “Capillary electrophoretic determination of DNA damage markers: content of 8-hydroxy-2' -deoxyguanosine and 8-nitroguanine in urine," Journal of Chromatography B, vol. 879, no. 32, pp. 38183822, 2011.

[24] J. Langmaier, Z. Samec, and E. Samcová, "Electrochemical oxidation of 8-oxo- $2^{\prime}$-deoxyguanosine on glassy carbon, gold, platinum and tin(IV) oxide electrodes," Electroanalysis, vol. 15, no. 19, pp. 1555-1560, 2003.

[25] I. Rebelo, J. A. P. Piedade, and A. M. O. Brett, "Electrochemical determination of 8-oxoguanine in the presence of uric acid," Bioelectrochemistry, vol. 63, no. 1-2, pp. 267-270, 2004.

[26] A. M. O. Brett, J. A. P. Piedade, and S. H. P. Serrano, "Electrochemical oxidation of 8-oxoguanine," Electroanalysis, vol. 12, no. 12, pp. 969-973, 2000.

[27] T.-H. Li, W.-L. Jia, H.-S. Wang, and R.-M. Liu, "Electrochemical performance of 8-hydroxy-2I-deoxyguanosine and its detection at poly(3-methylthiophene) modified glassy carbon electrode," Biosensors and Bioelectronics, vol. 22, no. 7, pp. 1245-1250, 2007.

[28] L. Jia and H. Wang, "Electrochemical reduction synthesis of graphene/Nafion nanocomposite film and its performance on the detection of 8-hydroxy-2' -deoxyguanosine in the presence of uric acid," Journal of Electroanalytical Chemistry, vol. 705, pp. 37-43, 2013.

[29] A. Gutiérrez, S. Osegueda, S. Gutiérrez-Granados, A. Alatorre, M. G. García, and L. A. Godínez, "Amperometric detection and quantification of 8-hydroxy-2' -deoxyguanosine (8-OHdG) using dendrimer modified electrodes," Electroanalysis, vol. 20, no. 21, pp. 2294-2300, 2008.

[30] A. Gutiérrez, S. Gutiérrez, G. García, L. Galicia, and G. A. Rivas, "Determinatiom of 8-hydroxy-2' -deoxyguanosine using electrodes modified with a dispersion of carbon nanotubes in polyethylenimine," Electroanalysis, vol. 23, no. 5, pp. 1221-1228, 2011.

[31] S. Hu and C. Hu, "Carbon nanotube-based electrochemical sensors: principles and applications in biomedical systems," Journal of Sensors, vol. 2009, Article ID 187615, 40 pages, 2009.

[32] M. Penza, G. Sberveglieri, W. Wlodarski, and Y. Li, "Nanomaterials for chemical sensing technologies," Journal of Sensors, vol. 2009, Article ID 924941, 2 pages, 2009.
[33] J. Wang, "Carbon-nanotube based electrochemical biosensors: a review," Electroanalysis, vol. 17, no. 1, pp. 7-14, 2005.

[34] W. Yang, P. Thordarson, J. J. Gooding, S. P. Ringer, and F. Braet, "Carbon nanotubes for biological and biomedical applications," Nanotechnology, vol. 18, no. 41, Article ID 412001, 2007.

[35] P. M. Ajayan, "Nanotubes from carbon," Chemical Reviews, vol. 99, no. 7, pp. 1787-1799, 1999.

[36] S. N. Kim, J. F. Rusling, and F. Papadimitrakopoulos, "Carbon nanotubes for electronic and electrochemical detection of biomolecules," Advanced Materials, vol. 19, no. 20, pp. 32143228, 2007.

[37] Q. Zhao, Z. H. Gan, and Q. K. Zhuang, "Electrochemical sensors based on carbon nanotubes," Electroanalysis, vol. 14, no. 23, pp. 1609-1613, 2002.

[38] J. Wang, M. Li, Z. Shi, N. Li, and Z. Gu, "Direct electrochemistry of cytochrome $\mathrm{c}$ at a glassy carbon electrode modified with single-wall carbon nanotubes," Analytical Chemistry, vol. 74, no. 9, pp. 1993-1997, 2002.

[39] H. X. Luo, Z. J. Shi, N. Q. Li, Z. N. Gu, and Q. K. Zhuang, "Investigation of the electrochemical and electrocatalytic behavior of single-wall carbon nanotube film on a glassy carbon electrode," Analytical Chemistry, vol. 73, no. 5, pp. 915-920, 2001.

[40] M. Musameh, J. Wang, A. Merkoci, and Y. H. Lin, "Lowpotential stable NADH detection at carbon-nanotube-modified glassy carbon electrodes," Electrochemistry Communications, vol. 4, no. 10, pp. 743-746, 2002.

[41] G.-C. Zhao, L. Zhang, X.-W. Wei, and Z.-S. Yang, "Myoglobin on multi-walled carbon nanotubes modified electrode: direct electrochemistry and electrocatalysis," Electrochemistry Communications, vol. 5, no. 9, pp. 825-829, 2003.

[42] B. Rezaei, O. Rahmanian, and A. A. Ensafi, "An electrochemical sensor based on multiwall carbon nanotubes and molecular imprinting strategy for warfarin recognition and determination," Sensors and Actuators, B: Chemical, vol. 196, pp. 539-545, 2014.

[43] Z. H. Fan and D. J. Harrison, "Permeability of glucose and other neutral species through recast perfluorosulfonated ionomer films," Analytical Chemistry, vol. 64, no. 11, pp. 1304-1311, 1992.

[44] K. B. Wu and S. S. Hu, "Electrochemical study and selective determination of dopamine at a multi-wall carbon nanotubenafion film coated glassy carbon electrode," Microchimica Acta, vol. 144, no. 1-3, pp. 131-137, 2004.

[45] H. J. Chen, Y. L. Wang, Y. Liu, Y. Z. Wang, L. Qi, and S. J. Dong, "Direct electrochemistry and electrocatalysis of horseradish peroxidase immobilized in Nafion-RTIL composite film," Electrochemistry Communications, vol. 9, no. 3, pp. 469474, 2007.

[46] J. Wang, M. Musameh, and Y. Lin, "Solubilization of carbon nanotubes by Nafion toward the preparation of amperometric biosensors," Journal of the American Chemical Society, vol. 125, no. 9, pp. 2408-2409, 2003.

[47] Y. Zhang, Z. Shi, Z. Gu, and S. Iijima, "Structure modification of single-wall carbon nanotubes," Carbon, vol. 38, no. 15, pp. 20552059, 2000.

[48] R. R. Moore, C. E. Banks, and R. G. Compton, "Basal plane pyrolytic graphite modified electrodes: comparison of carbon nanotubes and graphite powder as electrocatalysts," Analytical Chemistry, vol. 76, no. 10, pp. 2677-2682, 2004.

[49] J. Tkac and T. Ruzgas, "Dispersion of single walled carbon nanotubes. Comparison of different dispersing strategies for preparation of modified electrodes toward hydrogen peroxide 
detection," Electrochemistry Communications, vol. 8, no. 5, pp. 899-903, 2006.

[50] J. Li, S. Guo, Y. Zhai, and E. Wang, "High-sensitivity determination of lead and cadmium based on the Nafion-graphene composite film," Analytica Chimica Acta, vol. 649, no. 2, pp. 196201, 2009.

[51] Y. Guan, G. Zhou, and J. Ye, "Fast quantification of salivary 8hydroxy- 2 '-deoxyguanosine as DNA damage biomarker using CE with electrochemical detection," Chromatographia, vol. 77, no. 7-8, pp. 603-607, 2014. 

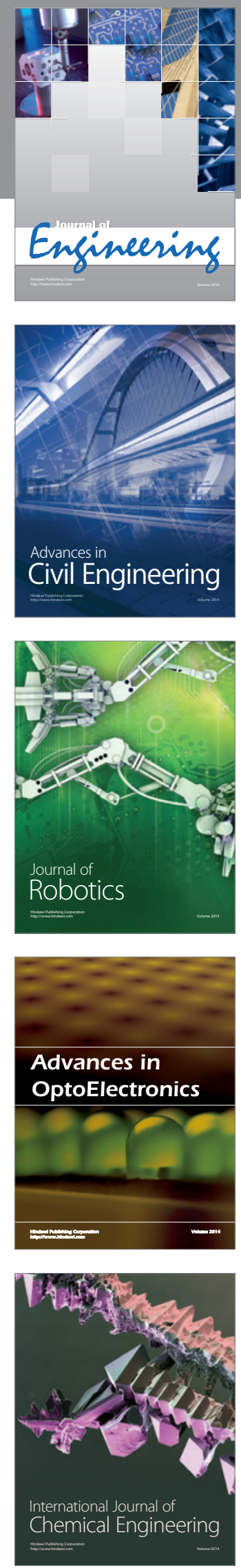

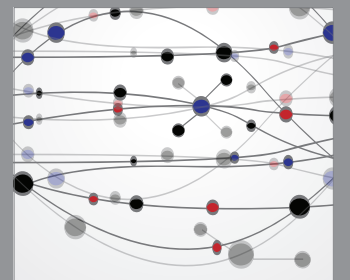

The Scientific World Journal
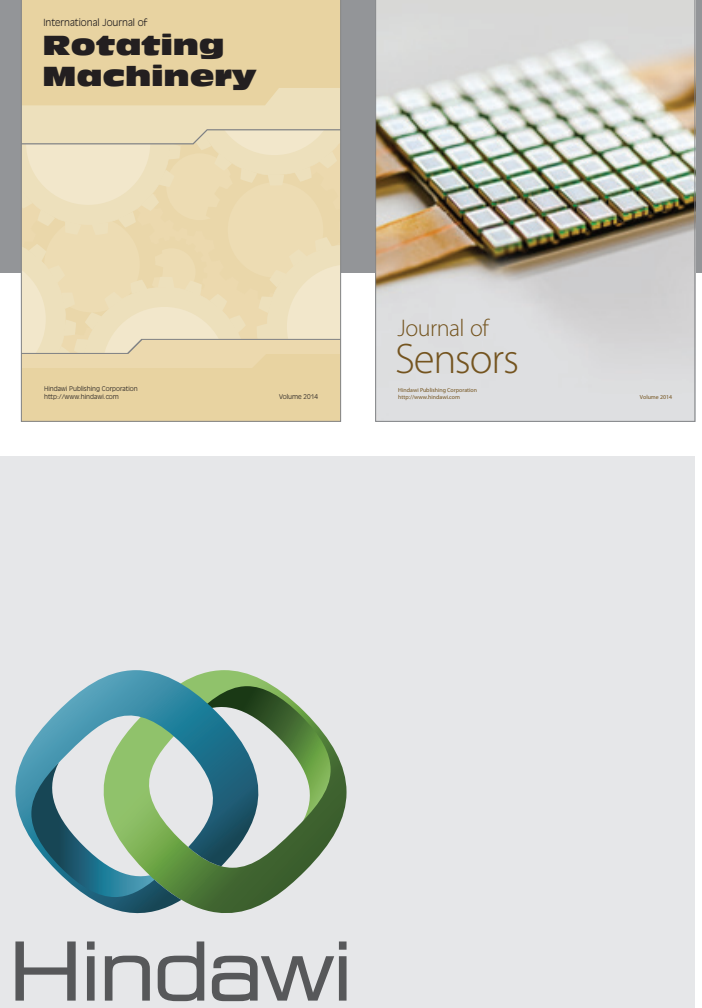

Submit your manuscripts at http://www.hindawi.com
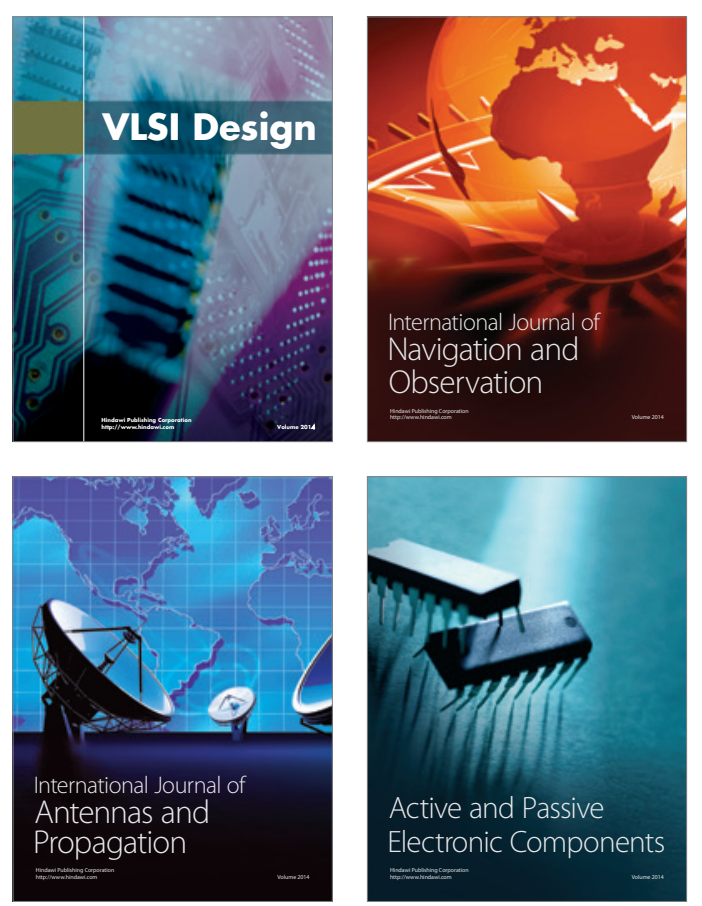
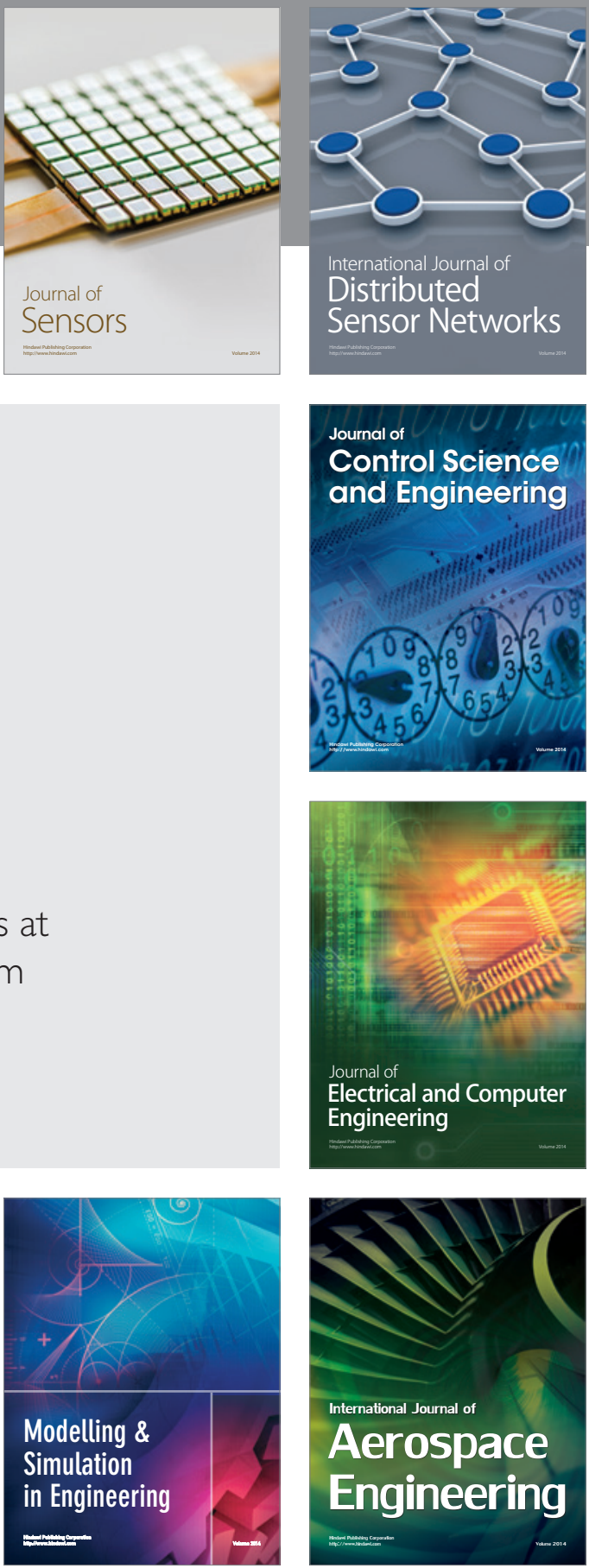

Journal of

Control Science

and Engineering
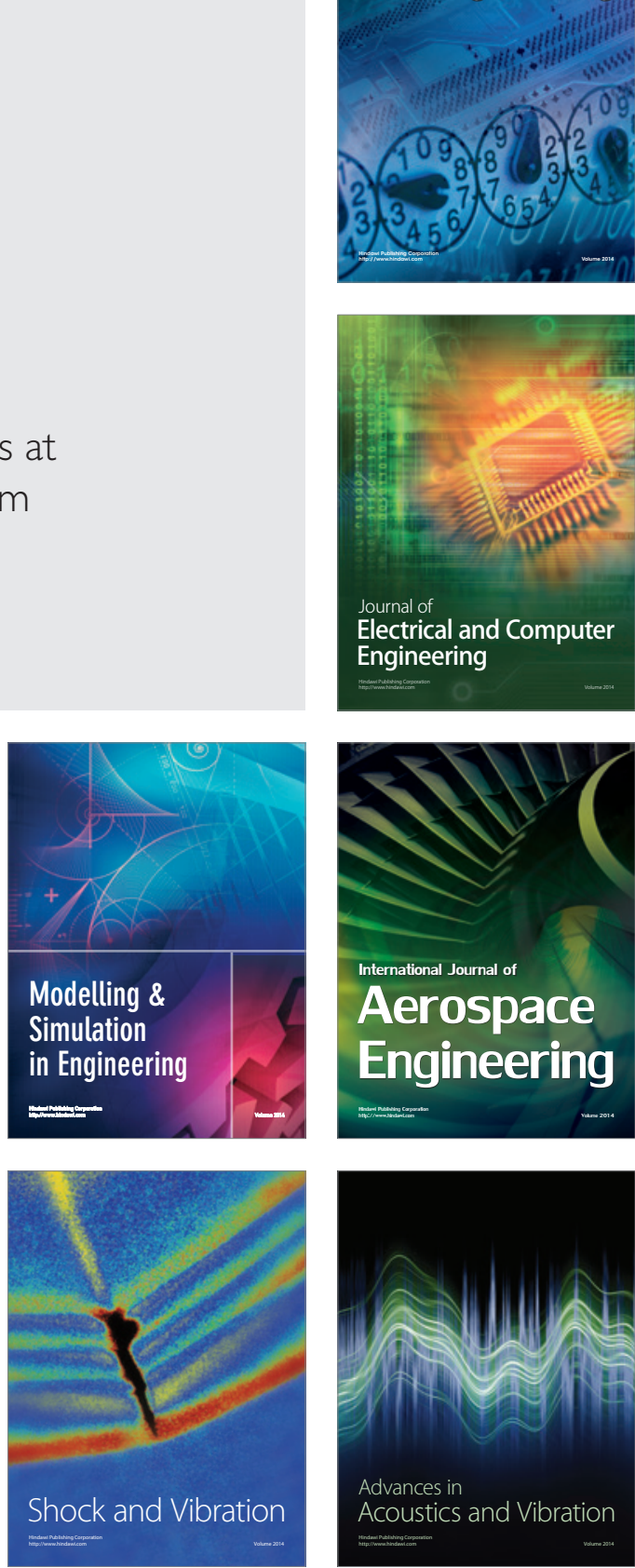